International Journal of Chemical and Process Engineering Research

2014 Vol. 1, No. 2, pp. 10-18

$\operatorname{ISSN}(e): 2313-0776$

$\operatorname{ISSN}(p): 2313-2558$

DOI: $10.18488 /$ journal.65/2014.1.2/65.2.10.18

(C) 2014. Conscientia Beam. All Rights Reserved.

D. CrossMark

\title{
ELECTROCHEMICAL STUDY OF CORROSION INHIBITION ACTION OF SULPHADOXINE AND PYRIMETHAMINE ON MILD STEEL IN ACIDIC MEDIUM
}

\section{A. Akpan ${ }^{1}$--- N. O. Offiong ${ }^{2}$}

${ }^{1,2}$ Corrosion and Materials Science Unit, Department of Chemistry, University of Uyo, Nigeria

\begin{abstract}
The corrosion inhibition action of sulphadoxine and pyrimethamine, which is being sold under the trade name "Antimal" as a single antimalarial drug was used as low cost and eco-friendly inhibitor for acid corrosion of mild steel monitored by means of an electrochemical technique at room temperature $\left(30^{\circ} \mathrm{C}\right)$. It was found that the polarization resistance of the inhibitor was directly proportional to the concentration of the inhibitor -making the metal more resistant to corrosion at higher inhibitor concentrations. Also, the inhibition efficiency was found to increase with rise in concentration of the inhibitor. The experimental data were found to fit better for Temkin isotherm which illustrates multilayer chemisorption. However, significant correlation $\left(R^{2}=0.76\right)$ was found for Frumkin isotherm indicating possible amphiphilic interactions from alkyl substituents on the inhibitor molecules.
\end{abstract}

Keywords: Electrochemical polarization technique, Corrosion inhibition, Antimal drug, Sulfadoxine, Pyrimethamine.

\section{INTRODUCTION}

The durability and, in consequence, the integrity of metals have thus far been challenged by deleterious effects of corrosion. Recent industrial events show many structural failures and leakages as a result of interaction of metals with aqueous and non-aqueous environments. Such failures and leakages have caused industrial and economic setbacks.

In a bid to significantly reduce the adverse effect of these environments on metals, scientists as well as engineers have developed chemical corrosion inhibitors in metal-aggressive systems. For instance, the uses of organic and inorganic inhibitors for metal corrosion in different media have been reported by several authors [1-5].

According to Akpan, et al. [6], the summary of the search for efficient corrosion inhibitors seems to reveal that much effort and expectations are focused on synthetic organic and inorganic 
substances whereas the discovery of satisfactory inhibitor for specific metal surfaces still remain a mystery.

Recently, researchers have shown that drugs, most of which have potential adsorption sites for corrosion inhibition, may be used for metal protection in aggressive media. For example the use of antifungal drugs [7], sulpha drugs [8], and anti-bacterial drugs [9,10] as probable corrosion inhibitors have been reported. In continuation for the search for efficient corrosion inhibitors, the authors in this present work provide an alternative to both synthetic substances and natural extracts as corrosion inhibitors and present the results of the electrochemical and synergistic studies of the corrosion inhibition of an antimalarial drug (consisting of sulphadoxine and pyrimethamine compounds) on mild steel in acidic medium.

\section{EXPERIMENTAL}

\subsection{Inhibitors}

Antimal is an antimalarial drug consisting of two compounds, sulphadoxine and pyrimethamine each constituting $500 \mathrm{mg}$ and $25 \mathrm{mg}$ of the drug respectively. Sulphadoxine has a molecular formula of $\mathrm{C}_{12} \mathrm{H}_{14} \mathrm{~N}_{4} \mathrm{O}_{4} \mathrm{~S}(\mathrm{~m} . \mathrm{w} .=310 \mathrm{~g} / \mathrm{mol})$ while pyrimethamine has $\mathrm{C}_{12} \mathrm{H}_{12} \mathrm{ClN}_{4}$ (m.w. $=248.5 \mathrm{~g} / \mathrm{mol}$ ). The "Antimal" drug tablets used in this study were purchased locally and were used without further modification or purification. Each tablet contained $500 \mathrm{mg}$ of $\mathrm{N}^{\prime}(5,6-$ dimethoxy-4-pyrimethanyl) sulphanilamide (sulphadoxine) and $25 \mathrm{mg}$ of 2 , 4-diamino-5-( $p$ chlorophenyl)-6-ethylpyrimidine (pyrimethamine). Therefore, the combined molecular weight of a tablet is $558.5 \mathrm{~g} / \mathrm{mol}$ and their structures are as shown in Figure 1 below:

Fig-1. Chemical structures of the inhibitors

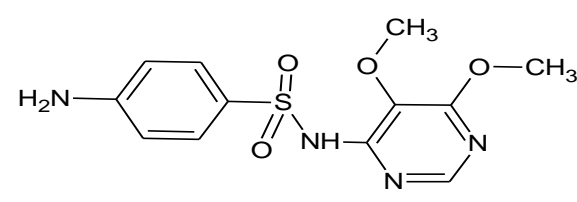

Sulphadoxine<smiles>CCc1nc(N)nc(N)c1-c1ccc(Cl)cc1</smiles>

Pyrimethamine

The molar concentration of the drug was determined based on their molar mass as well as their mass dissolved in the corrodent medium.

\subsection{Corrosive Medium}

Commercially available analytical grade of $\mathrm{HCl}$ was prepared by dilution method and used without further purification. The concentration of $\mathrm{HCl}$ used in this study was $0.1 \mathrm{M}$.

\subsection{Specimens}

The sheets of commercially available mild steel (of $98 \%$ purity) used for this study were identified and obtained locally. Each sheet was $0.10 \mathrm{~cm}$ in thickness. The sheets were mechanically 
pressed cut into $3 \mathrm{~cm}$ by $3 \mathrm{~cm}$ coupons with small hole of about $5 \mathrm{~mm}$ diameter near the upper edge to help hold them with glass hooks. The mild steel coupons were polished to remove unwanted impurities using emery papers, degreased with acetone, washed in double distilled water and airdried before use $[11,12]$.

\subsection{Electrochemical Measurements}

A conventional three-electrode system consisting of mild steel as the working electrode, carbon electrode as an auxiliary electrode and saturated calomel as reference electrode (SCE) was used for the measurements. The corrosion potential of the mild steel coupons was monitored using a variable voltage, DC power supply (AC mV metre, 2channel model GVT 427). The potential change of the working electrode which occurred as a result of the external current was measured by means of the reference electrode (SCE) and a voltmeter. A detail description of this method can be found elsewhere [13].

The voltage of the variable supply was adjusted until a resistance which corresponds to the current supplied by the DC source was obtained. Readings were recorded for corrosion process in $0.1 \mathrm{M} \mathrm{HCl}$ and with several concentrations of the drug. Polarization resistance ( $\mathrm{Rp}$ ) was obtained from the slope of the linear polarization regions of the polarization curves. According to Achary, et al. [14] polarization resistance $(\mathrm{Rp})$ can be estimated using the equation below:

$R p=A \times($ slope of plot of E versus $I)$

where $\mathrm{A}$ is the surface area of the electrode, $\mathrm{E}$ is the potential and $\mathrm{I}$ is the current.

Corrosion rate $(\mathrm{CR})$ was computed using the equation below [15]:

$C R=\frac{K}{R p}$

where $\mathrm{K}$ is the Stern-Geary constant which depends on the type of metal and experimental conditions. This constant equals 0.026V for similar system reported by Gerengi and Sahin [16].

\subsection{Adsorption Isotherm}

Adsorption studies were performed by testing experimental data for Temkin [17], Langmuir [4], Frumkin and Flory-Huggins isotherms [18] with their empirical relationships expressed in equations 3, 4, 5 and 6 respectively.

$\ln K C=a \theta$

$C / \theta=1 / K+C$

$\log \left\{C \times\left(\frac{\theta}{1-\theta}\right)\right\}=2.303 \log K+2 a \theta$ 
$\log \left(\frac{\theta}{C}\right)=\log K+x \log (1-\theta)$

where $\mathrm{C}$ is the inhibitor concentration, and $\mathrm{K}$ is the adsorptive equilibrium constant, $a$ is the interaction parameter, $\theta$ is the surface coverage and $x$ is the size parameter and is a measure of the number of adsorbed water molecules substituted by a given inhibitor molecule [18].

\section{RESULTS AND DISCUSSION}

\subsection{Linear Polarization Resistance}

Polarization measurements are important in electrochemical studies of metals because they permit investigation of the reaction mechanism as well as the kinetics of the corrosion process [19].

In this technique, the values of change in current as a result of applied potential obtained from electrochemical measurements are used. Useful data are obtained from the slopes extrapolated from the initial linear region of the polarization curves of the potential versus current plots [20].

Polarization resistance $(\mathrm{Rp})$ values were calculated using equation 1 . The slopes of the linear polarization regions (LPR) of the polarization curves as shown in Figure 2 gave access to the computation of Rp. The values of the polarization resistance are shown in Table 1.

Fig-2. Electrochemical polarization curves for the corrosion of mild steel in $0.1 \mathrm{M} \mathrm{HCl}$ for different concentration of the inhibitor.

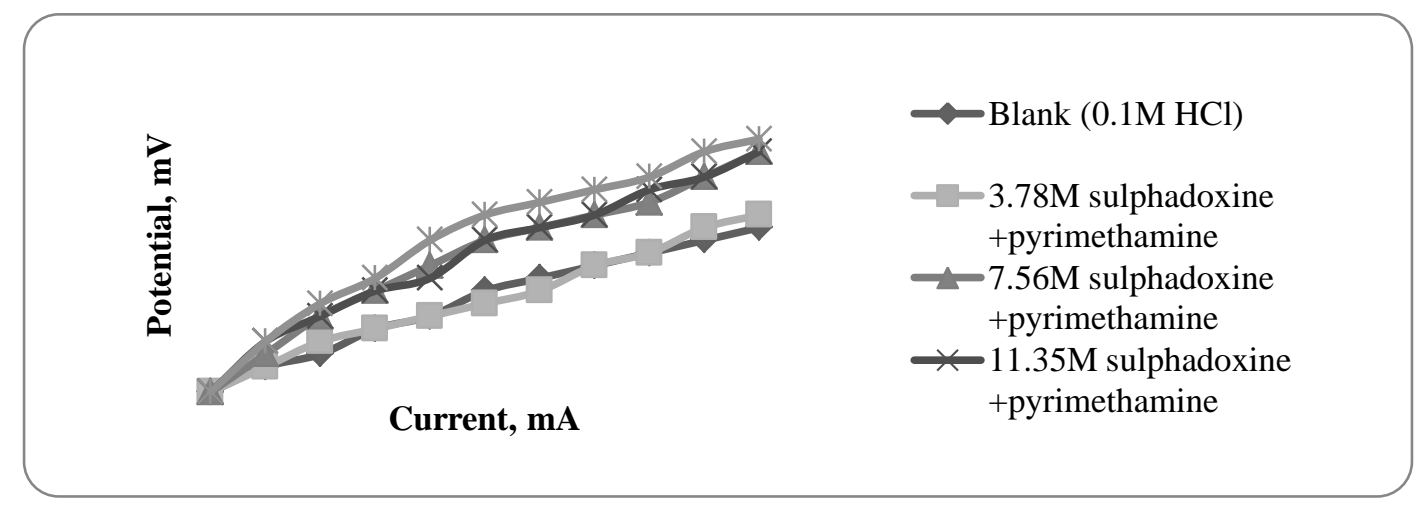

As observed from Table 1, the polarization resistance increases with increase in the inhibitor concentration. Since, high Rp implies high corrosion resistance [18], it follows that the introduction of inhibitors into the corrodent mixture significantly made the mild steel corrosion resistant.

Also, as seen in Table 1, the estimated corrosion rate reduced with the addition of inhibitors into the corrodent. The corrosion rate decreased with an increase in the inhibitor concentration. 
The gradual decrease in the corrosion rate is probably due to the passivity acquired by the metal specimen as a result of covering of a thin film of the inhibitor on the metal-corrodent interface.

Table-1. Calculated electrochemical and inhibition parameters of mild steel corrosion in $0.1 \mathrm{M}$ $\mathrm{HCl}$ in the absence and presence of the inhibitor

\begin{tabular}{lllll}
\hline $\begin{array}{l}\text { System/ } \\
\text { Concentration }(\mathbf{M})\end{array}$ & \multicolumn{2}{l}{ Corrosion Parameters } \\
\hline & $\mathbf{R p}\left(\mathbf{\Omega c m}^{2}\right)$ & $\mathbf{C R}\left(\times \mathbf{1 0}^{-2} \mathbf{m p} / \mathbf{y}\right)$ & IE (\%) & $\boldsymbol{\theta}$ \\
\hline Blank $(0.1 \mathrm{M} \mathrm{HCl})$ & 0.248 & 10.48 & - & - \\
\hline $3.78 \times 10^{-3}$ & 0.257 & 10.12 & 3.5 & 0.035 \\
\hline $7.56 \times 10^{-3}$ & 0.336 & 7.74 & 35.65 & 0.357 \\
\hline $11.35 \times 10^{-3}$ & 0.337 & 7.71 & 35.65 & 0.357 \\
\hline $15.13 \times 10^{-3}$ & 0.360 & 7.22 & 45.73 & 0.457 \\
\hline
\end{tabular}

\subsection{Corrosion Inhibition Efficiency}

The inhibition efficiency of the inhibitor was estimated using equation 7 [9]:

$\% I E=\frac{R_{p}-R_{p}^{I}}{R_{p}^{I}} \times 100$

where $\mathrm{R}_{\mathrm{p}}$ and $R_{p}^{I}$ are the polarization resistances in the presence and absence of inhibitors, respectively. The values of the inhibitor efficiency are shown in Table 1 . It is seen that the efficiency of the inhibitor increased with a corresponding increase in the concentration of the inhibitors.

\subsection{Adsorption Isotherm}

The inhibitive action of a corrosion inhibitor is believed to be by adsorption of some active centres on its molecular structure upon the surfaces of the metal. By this, it therefore becomes a good practice to assess the adsorption mode of the compound by subjecting the experimental data to several adsorption isotherm tests. The degree of surface coverage $(\theta)$ (Table 1) was derived from the inhibition efficiency (\%IE) using a modified equation by Singh, et al. [21] as shown below:

$\theta=\frac{\% I E}{100}$

Careful data treatment performed for Temkin, Langmuir, Frumkin and Flory-Huggins isotherms, would show the most fitting isotherm with maximum regression coefficients $\left(\mathrm{R}^{2}\right)$. This was done following previously reported procedures described in details by Khadom, et al. [4],Nwabanne and Okafor [18],Maayta, et al. [22]. For Temkin isotherm test, the degree of surface coverage $(\theta)$ was plotted against the logarithm of the inhibitor concentrations $(\log C)$ with $\mathrm{R}^{2}$ equals to 0.904 , the Langmuir isotherm was tested by plotting $\mathrm{C} / \theta$ against $\mathrm{C}$ with $\mathrm{R}^{2}$ equals to 0.4773 , the Frumkin isotherm was tested by plotting $\log [\mathrm{C} \times(\theta / \theta-1)]$ against $\theta$ with $\mathrm{R}^{2}$ equals to 0.7695 , while the Flory-Huggins isotherm was tested by plotting $\log (\theta / \mathrm{C})$ against $\log (1-\theta)$ with 
$\mathrm{R}^{2}$ equals to 0.566. In this experiment, the most significant correlations were found for Frumkin and Temkin isotherms with $\mathrm{R}^{2}$ greater than 0.76 and 0.90 respectively as shown in Figures $3 \mathrm{a}$ and 3b. Other isotherm plots had lower $\mathrm{R}^{2}$ below 0.60 .

Fig-3a. Frumkin isotherm for adsorption of sulphadoxine and pyrimethamine drug on mild steel in $0.1 \mathrm{M} \mathrm{HCl}$

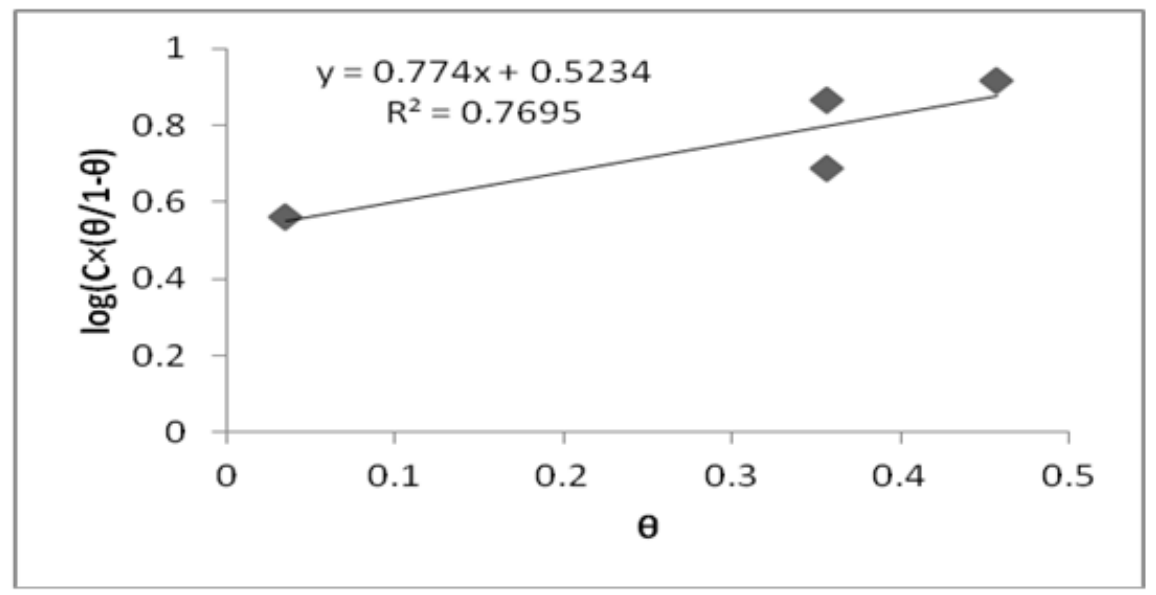

Fig-3b. Temkin isotherm for adsorption of sulphadoxine and pyrimethamine drug on mild steel in $0.1 \mathrm{M} \mathrm{HCl}$

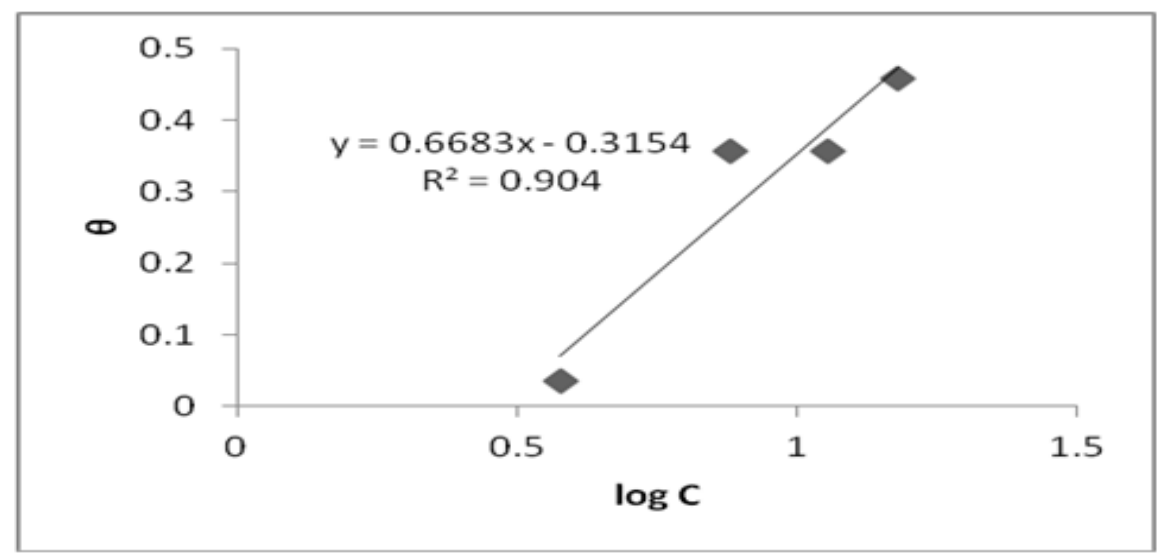

With the maximum correlation found for Temkim isotherm plots, it may be assumed that the predominant adsorption mode of the studied inhibitor compounds was multilayer chemisorptions $[23,24]$. On the other hand, the significant correlation of the experimental data predicted for the Frumkin isotherm, however minimal, cannot be ignored. This is because the Frumkin isotherm illustrates a strongly attractive interaction between the metal surface and the amphiphilic hydrocarbon tails [25] present on the structures of the two compounds that make up the drug tablets, especially the methyl group on pyrimethamine. This illustration can further be explained 
by a proposed possible orientation of the molecules towards the metal surfaces as depicted in Figure 4 where the inhibitor molecules attack the metal surface through different segments of the molecular structure. Also, this observation may provide a pointer towards the understanding of the corrosion inhibition mechanism.

\subsection{Mechanism of Corrosion Inhibition}

As discussed previously, the inhibition mechanism of the tested drug tablet is suspected to be highly influenced by interaction of the two compounds with themselves, the electrolyte and the monitored electrode. The inhibition action of organic compounds as corrosion inhibitors may be related to the concept of molecular adsorption on the metal surface [26]. The action of the inhibitor molecules may be due to the presence of $\mathrm{N}, \mathrm{S}, \mathrm{O}$ heteroatoms as well as the aromatic rings which contain $\pi$-electrons in their molecular structures. The collaborative action of the two molecular compounds leads to increase in the bulkiness of the inhibitors which in turn enhances the wider coverage on the metal surface. Furthermore, as shown in Figure 4, due to the presence of many heteroatoms (with lone pairs of electrons) as potential adsorption centres throughout the structure of the molecules, it is suspected that possible coordination between the inhibitor-metal interfaces may have also occurred. This further enhances the degree of adsorption between the inhibitor molecules and the metal surfaces.

Fig-4. Arrows depicting the orientation of the inhibitor molecules towards the mild steel (MS) surface

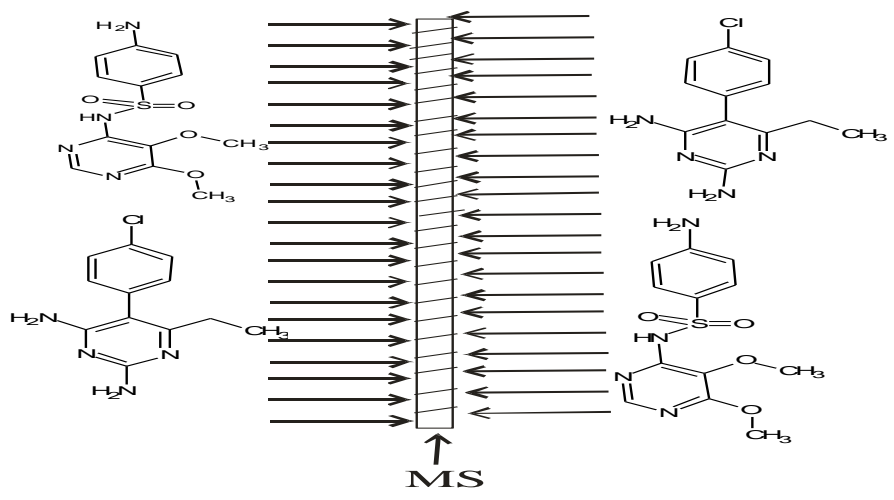

\section{CONCLUSION}

Sulphadoxine and pyrimethamine significantly reduced the corrosion rate of mild steel in $0.1 \mathrm{M}$ solution of hydrochloric acid solution at the concentrations studied. The polarization resistance of the metal in the aggressive ions environment was found to have increased on the introduction of the drug tablets. The behaviour of the inhibitor molecules indicates the action of their molecular structure. The experimental data fits the Temkin adsorption isotherm which indicated multilayer chemisorption. This may be due to the action and interaction of the two 
molecular species (sulphadoxine and pyrimethamine) introduced into the corrosive medium. However, experimental data had significant correlation $\left(\mathrm{R}^{2}=0.76\right)$ with the Frumkin isotherm and it is assumed that the hydrocarbon tails on the inhibitors had strong interactions with the metal surface.

\section{REFERENCES}

[1] I. A. Akpan and N. O. Offiong, "Effect of ethanolamine and ethylamine on the entropy content of the corrosion of mild steel in 1M tetraoxosulphate (VI) acid solution," Chemistry and Materials Research, vol. 2, pp. 40-47, 2012.

[2] B. M. Mistry, N. S. Patel, and S. Jauhari, "Heterocyclic organic derivative as corrosion inhibitor for mild steel in 1N HCl," Archives of Applied Science Research, vol. 3, pp. 300-308, 2011.

[3] P. S. Desai and S. M. Kapopara, "Inhibiting effect of anisidines on corrosion of aluminium in hydrochloric acid," Indian Journal of Chemical Technology, vol. 16, pp. 486-491, 2009.

[4] A. A. Khadom, A. S. Yaro, A. S. AlTaie, and A. A. H. Kadum, "Electrochemical, activations and adsorption studies for the corrosion inhibition of low carbon steel in acidic media," Portugaliae Electrochimica Acta, vol. 27, pp. 699-712, 2009.

[5] Q. B. Zhang and Y. X. Hua, "Corrosion inhibition of mild steel by alkylimidazolium ionic liquids in hydrochloric acid," Electrochimica Acta, vol. 54, pp. 1881-1887, 2009.

[6] I. A. Akpan, A. S. Ekop, and M. I. Udoh, "The kinetic study of corrosion of galvanised steel in tetraoxosulphate (VI) acid solution and its inhibition by bile salt," Materials Science An Indian Journal, vol. 4, pp. 145-149, 2008.

[7] I. B. Obot, N. O. Obi-Egbedi, and S. A. Umoren, "Antifungal drugs as corrosion inhibitors for aluminium in 0.1M HCl," Corrosion Science, vol. 51, pp. 1868-1875, 2009.

[8] M. M. El-Naggar, "Corrosion inhibition of mild steel in acidic medium by some sulfa drugs compounds," Corrosion Science, vol. 47, pp. 2226-2236, 2007.

[9] M. Abdallah, "Antibacterial drugs as corrosion inhibitors for corrosion of aluminium in hydrochloric solution," Corrosion Science, vol. 46, pp. 1981-1996, 2004.

[10] A. S. Fouda, H. A. Mostafa, and H. M. El-Abbasy, "Antibacterial drugs as inhibitors for the corrosion of stainless steel type 304 in $\mathrm{HCl}$ solution," Journal of Applied Electrochemistry, vol. 40, pp. 163-173, 2010.

[11] A. Kumar, "Corrosion inhibition of mild steel in hydrochloric acid by sodium lauryl sulfate (SLS)," E-Journal of Chemistry, vol. 5, pp. 275-280, 2008.

[12] H. Ashassi-Sorkhabi and D. Seifzadeh, "The inhibition of steel corrosion in hydrochloric acid solution by juice of prunus cerasus," International Journal of Electrochemical Science, vol. 1, pp. 92-98, 2006.

[13] B. E. Wilde and E. Williams, "The use of current/voltage curves for the study of localized corrosion and passivity breakdown on stainless steels in chloride media," Electrochimica Acta, vol. 16, pp. 1971-1985, 1971 . 
[14] G. Achary, H. P. Sachin, Y. Arthoba Naik, and T. V. Venkatesha, "The corrosion inhibition of mild steel by 3-formyl-8-hydroxy quinoline in hydrochloric acid medium," Materials Chemistry and Physics, vol. 107, pp. 44-50, 2008.

[15] A. O. James, N. C. Oforka, and O. K. Abiola, "Inhibition of acid corrosion of mild steel by pyridoxal and pyridoxol hydrochlorides," International Journal of Electrochemical Science, vol. 2, pp. 278-284, 2007.

[16] H. Gerengi and H. I. Sahin, "Schinopsis lorentzii extracts as green corrosion inhibitor for low carbon steel in $1 \mathrm{M} \mathrm{HCl}$ solution," Industrial \& Engineering Chemistry Research, vol. 51, pp. 780-787, 2012.

[17] M. Abdallah, H.E., M. A. Radwan, and E. Abdfattah, "Polyethylene glycol compounds as corrosion inhibitors for aluminium in 0.5M hydrochloric acid solutions," Journal of American Science, vol. 8, pp. 49-55, 2012 .

[18] J. T. Nwabanne and V. N. Okafor, "Inhibition of the corrosion of mild steel in acidic medium by Vernonia amygdalina: Adsorption and thermodynamics study," Journal of Emerging Trends in Engineering and Applied Sciences, vol. 2, pp. 619-625, 2011.

[19] M. Stern and A. L. Geary, "Electrochemical polarization I. A theoretical analysis of the shape of polarization curves," Journal of The Electrochemical Society, vol. 104, pp. 56-63, 1957.

[20] M. Stern, "A method for determining corrosion rates from linear polarization data," Corrosion, vol. 14, pp. 60-64, 1958.

[21] M. R. Singh, K. Bhrara, and G. Singh, "The inhibitory effect of diethanolamine on corrosion of mild steel in 0.5M sulphuric acidic medium," Portugaliae Electrochimica Acta, vol. 26, pp. 479-492, 2008.

[22] A. K. Maayta, M. M. Fares, and A. F. Al-Shawabkeh, "Influence of linear alkyl benzene sulphonate on corrosion of iron in presence of magnetic field: Kinetic and thermodynamic parameters," International Journal of Corrosion, 2010.

[23] K. C. Emregul and O. Atakol, "Corrosion inhibition of mild steel with Schiff base compounds in $1 \mathrm{M} \mathrm{HCl,"} \mathrm{Materials} \mathrm{Chemistry} \mathrm{and} \mathrm{Physics,} \mathrm{vol.} \mathrm{82,} \mathrm{pp.} \mathrm{188-193,} 2003$.

[24] S. A. Abd El-Maksoud, "The effect of organic compounds on the electrochemical behaviour of steel in acidic media. A review," International Journal of Electrochemical Science, vol. 3, pp. 528-555, 2008.

[25] J. S. Facci, "Modification of platinum electrode surfaces with adsorbed (Ferrocenylmethyl) dimethyloctadecylammonium hexafluorophosphate," Langmuir, vol. 3, pp. 525-530, 1987.

[26] S. Chitra, K. Parameswari, C. Sivakami, and A. Selvaraji, "Sulpha Schiff bases as corrosion inhibitors for mild steel in 1M sulphuric acid," Chemical Engineering Research Bulletin, vol. 14, pp. 1$6,2010$. 